\title{
Synthesis, Characterization And Antimicrobial Activity of Copper-Metal Organic Framework (Cu- MOF) And Its Modification By Melamine
}

\section{A.S. Abdelmoaty ( $\square$ 3laasalah.86@gmail.com )}

National Research Center

\section{A.A. El-Beih}

National Research Center

\section{A.A. Hanna \\ National Research Center}

\section{Research Article}

Keywords: Metal Organic Framework (MOF), Antimicrobial, Characterization, Surface area and Thermal behavior

Posted Date: November 19th, 2021

DOI: https://doi.org/10.21203/rs.3.rs-1069732/v1

License: (9) This work is licensed under a Creative Commons Attribution 4.0 International License. Read Full License

Version of Record: A version of this preprint was published at Journal of Inorganic and Organometallic Polymers and Materials on January 10th, 2022. See the published version at https://doi.org/10.1007/s10904-021-02187-8. 


\section{Abstract}

Copper- Metal organic framework (Cu-MOF) and melamine/ Cu-MOF (MCu-MOF) samples were prepared by the hydrothermal process. The produced powder was dried and characterized by using the FTIR, X-ray techniques. The thermal gravimetry $(\mathrm{TG})$ analysis was performed to detect the thermal stability of the product. On other hand, the morphology and the surface area of the powder were carried. The bioactivity of the powder was carried by measuring the inhibition zone diameter around samples in $(\mathrm{mm})$. The results of characterization showed that the formation of $\mathrm{Cu}-\mathrm{MO}$ and melamine/ Cu-MOF in crystalline state in both samples, the surface area of Cu-MOF is equal to $1350 \mathrm{~m}^{2} \mathrm{~g}^{-1}$ while increase to $1410 \mathrm{~m}^{2} \mathbf{g}^{-1}$ by incorporate by melamine into the Cu-MOF. The thermal behavior (TG) of the Cu-MOF showed three sequence stages attributed to the moisture evaporation, degradation of the Cu-MOF and forming the Cu-O as end product respectively. For melamine incorporated to Cu-MOF (MCU-MOF), the TG profile shows that the split of the main degradation into two parts resulting from the presence of melamine. The bioactivities of the both samples were tested against microbial strains. The results showed that the $\mathrm{Cu}$ MOF and MCu-MOF have insignificant antimicrobial activity against gram positive of bacteria and Fungi. While for gram negative of bacteria it is observed a considerable effect.

\section{Introduction}

Bacterial contamination creates many problems in many areas such as food, medical, water, soil, etc. These contaminations cause different disease for the human, environment and sometimes cause a microbial corrosion for the building and the construction units (1-6). The effects consumed a lot of efforts and cost. For these reasons many trials were done to reduce the bacterial effects. They used different chemicals, drugs and other developed materials. The literature survies show that the antibacterial materials can be divided in three classes, the first and oldest one in the organic or inorganic materials, the second class represents the metal oxides and the more advanced one is the metal organic frameworks (MOFs) (7-9).

In general MOFs refer to a porous class of materials from metal ions and organic fragments. In the MOF built, the inorganic cations distribute on node and the organic ligands as bridge, forming a three elemental structure with high porosity (10-12). The MOFs have many advantages such as form a frameworks skeleton, controllable pore size, low density and high homogeneous surface area and have different active functional groups.

It can be synthesized with commercially available reagents and possess the high surface area. Copper $(\mathrm{Cu})$ was selected as a classical transition metal which is considered to be one of the most attractive elements for use in the preparation of MOFs due to its abundance of resources, low cost, non-toxic properties, and most importantly high complexation strength (13).

Different methods were used to prepare MOFs matrix such as solvothermal process, hydrothermal synthesis, electro chemical techniques and microwave (14-17). MOFs can be used as metal ions source 
and liberate the inorganic cations such as $\mathrm{AG}, \mathrm{Zr}, \mathrm{Cu}$ and $\mathrm{Ni}$, These ions were continue release from the skeleton and forming an organic unit. Both the two fragments offer a durable antibacterial activity.

Several efforts were done to improve the physical and chemical properties of MOFs (18). These improvements mainly modified the structure of the molecules to increase the surface area. Melamine as a compound rich with nitrogen is prefer in this work to form melamine-MOF.

In this work, Cu-MOF was prepared, characterized and their antibacterial effects were studied. Moreover the effects of melamine- Cu-MOF on the structure and the bioactivity were studied.

\section{Experimental And Instruments}

\subsection{Instruments}

\subsubsection{X-ray diffraction (XRD) analysis}

X-ray diffraction (XRD) patterns were performed with power D8 ADVANCE diffractometer (Germany) using CuKa radiation $\left(1.542^{\circ} \mathrm{A}, 40 \mathrm{KV}, 40 \mathrm{~mA}\right)$ in the $2 \theta$ range of $4-80$. The acquisition parameters were as: a step size of 0.02 and a step time of $0.4 \mathrm{~s}$.

\subsubsection{Fourier transforms infrared (FTIR) spectroscopy}

FTIR spectra of the samples were obtained using a $\mathrm{KBr}$ disk technique and FTIR 6500 spectrometer (JASCO, Japan) in the range of $400-4000 \mathrm{~cm}^{-1}$

\subsubsection{The thermal analysis}

The thermal analysis (TGA) was performed by USA Berkin - Elmer thermogravimeter. Samples of approximately $10 \mathrm{mg}$ were heated from $50^{\circ} \mathrm{C}$ to $800^{\circ} \mathrm{C}$ with heating rate $10 / \mathrm{m}$ under a nitrogen atmosphere, and the flow of nitrogen was $50 \mathrm{ml} / \mathrm{min}$.

\subsubsection{Scanning electron microscope}

The surface morphologies of the samples were carried out using a Quanta 200 FEG scanning electron microscope (SEM) (Quanta) at an accelerating voltage of $30 \mathrm{kV}$.

\subsubsection{BET measurement}

Nitrogen adsorption-desorption measurements (BET method) were performed at liquid nitrogen temperature $\left(-196^{\circ} \mathrm{C}\right)$ with an Autosorb BET apparatus from Quanta chrome Corporation. The BET analysis procedure is automated and operates with the static volumetric technique. Before each measurement, the samples were degassed firstly at $200^{\circ} \mathrm{C}$ for 2 hours, at $5 \times 10^{-3}$ torr and then at room temperature for 2 hours, at $0.75 \times 10^{-6}$ torr. The isotherm methods were used to determine the specific surface areas using the BET equation. 


\subsubsection{Antimicrobial assay}

Antimicrobial activity of Cu-MOF and Melamine Cu-MOF (MCU-MOF) were evaluated against pathogenic Gram-positive bacteria (Bacillus subtilis ATCC6633, Lactobacillus cereus ATCC 14579 and Staphylococcus aureus ATCC29213), Gram-negative bacteria (Escherichia coli ATCC 25922 and Salmonella enterica ATCC 25566), and fungus (Aspergillus niger NRC53) by the agar diffusion technique. Bacteria were obtained from the American Type Culture Collection (ATCC) and Northern Regional Research laboratories (NRRL) while the fungal isolate was obtained from the culture collection of the Department of Chemistry of Natural and Microbial Products, National Research Centre, Cairo, Egypt. The microorganisms were passage at least twice to ensure purity and viability. The bacteria were maintained on nutrient agar medium and fungi were maintained on potato dextrose agar medium. About $50 \mathrm{mg}$ of the prepared powder samples were applied on the inoculated agar plates and incubated for $24 \mathrm{~h}$ at $37^{\circ} \mathrm{C}$ for bacteria and $72 \mathrm{~h}$ at $28^{\circ} \mathrm{C}$ for fungi. The antimicrobial effect was evaluated by measuring the inhibition zone diameter around samples in ( $\mathrm{mm})(19)$.

\subsection{Materials}

Anhydrous $\mathrm{N}$, $\mathrm{N}$-dimethylformamide (DMF, $99 \%)$, terephthalic acid $\left(\mathrm{H}_{2} \mathrm{BDC}, 98 \%\right)$, melamine, ethanol and copper nitrate trihydrate $\left(\mathrm{Cu}\left(\mathrm{NO}_{3}\right)_{2}, 99 \%\right)$ were obtained from Sigma Aldrich.

\subsubsection{Synthesis of Cu-MOF}

For the synthesis of Cu-MOF, $0.5 \mathrm{~g} \mathrm{H}_{2} \mathrm{BDC}$ and $2 \mathrm{~g} \mathrm{Cu}(\mathrm{NO} 3)_{2} \cdot 3 \mathrm{H}_{2} \mathrm{O}$ were fully dispersed in $38 \mathrm{~mL}$ (DMF: ethanol, $25: 13 \mathrm{~mL}$ ) and then the obtained solution was transferred to a $50 \mathrm{~mL}$ polytetrafluoroethylene lined stainless steel autoclave and placed in an oven at $100{ }^{\circ} \mathrm{C}$ for $36 \mathrm{~h}$. After that, it was taken out and cooling down at room temperature. Then, the product was separated and washed several times with DMF and water. Finally, Cu-MOF was obtained by drying the product at $80^{\circ} \mathrm{C}$ oven for $12 \mathrm{~h}(20)$.

\subsubsection{Synthesis of melamine Cu-MOF (MCu-MOF)}

Cu-MOF (0.5 g) and melamine (M) (1.0 g) were dispersed in $50 \mathrm{~mL}$ and $100 \mathrm{~mL}$ absolute ethanol, respectively. The two dispersions were mixed and sonicated for $10 \mathrm{~h}$ before the mixture was transferred to a flask. When the condensation reflux reaction had lasted for $24 \mathrm{~h}$ at $100^{\circ} \mathrm{C}$, the product was centrifugally rinsed with absolute ethanol and vacuum desiccation at $50^{\circ} \mathrm{C}$ overnight to obtain melaminecoated Cu-MOF (MCu-MOF).

\section{Results And Discussion}

\section{Characterization the prepared samples:-}

Both of the Cu-MOF and Melamine-MOF samples were characterized by using the following technique:- 


\subsection{Fourier transforms infrared (FTIR) spectroscopy}

The absorption bands of IR for both samples are illustrated in Fig. 1. For Cu-MOF powder, several bands were observed. For Fig. $1 \mathrm{a}$, at $488 \mathrm{~cm}^{-1}$ a specific peak characterized the Cu-O bonding was observed while another one at $721 \mathrm{~cm}^{-1}$ attributed to the stretching modes of Cu-O. Different peaks characterized the organic ligand were appeared. A peak between $663-766 \mathrm{~cm}^{-1}$ was observed on the IR chart. This peak may attribute to the aromatic ring of $\mathrm{H}_{2} \mathrm{BDC}$ (Terphthalic acid). Furthermore absorption band characterized the aromatic $\mathrm{C}=\mathrm{C}$ was observed at $1390 \mathrm{~cm}^{-1}$. Also, three absorption bands were observed at 970,1500 and $1640 \mathrm{~cm}^{-1}$ and it attributed to the vibration of $\mathrm{C}-\mathrm{O},-\mathrm{C}=\mathrm{C}-$ and $\mathrm{C}=0$ groups respectively of the $\mathrm{H}_{2} \mathrm{BDC}$. The appearance of three bands on the IR charts proved the successful preparation of Cu-MOF (20). Fig. 1b represents the melamine-MOF (MCU-MOF) sample. On the charts a series of the absorption bands at $3121,3324,3415$ and $3467 \mathrm{~cm}^{-1}$ characterized the stretching of the $\mathrm{NH}_{2}$ was observed and characterized the melamine molecule. It is noteworthy that the absorption bond at 1651 which attributed to $\mathrm{C}=\mathrm{O}$ stretching of the aromatic ligand was reduce by adding the melamine to the $\mathrm{Cu}-\mathrm{MOF}$, while the strong stretching vibration of $\mathrm{C}=\mathrm{N}$ bond was formed at the triazine ring (21). This finding emphasis the incorporation of the melamine into the Cu-MOF (22).

\subsection{X-Ray Diffraction spectroscopy (XRD)}

To study the structure and the crystallinity of the MOF and melamine-MOF samples, the powder was exposed to X-ray measurements. Fig. 2 represents the X-ray diffraction of the both samples. Firstly, it is observed that sharp definite peaks were observed and the sharpness and intensities of the peaks increase by introducing the melamine unite through the MOF network. On Fig. 2a for the Cu-MOF framework, a series of sharp peaks with definite intensities at 2-theta equal 7, 13.8, 15.7, 19.6, 30.0, 37.0, 42.5, 62.5 and 74 were appeared. The presence of their peaks corresponding the crystal planes (2 2 0), (2 22 ), (3 33 ), (4 2 0), (4 2 2), (7 73 3), (8 8 2), (4 40 ) and (5 3 3) crystal planes respectively in agreement with the previous work (23). For Fig. 2b, similar patterns were observed with two remarks:

1. The appearances of some bands indicate that the structure of the network still formed in spite of introducing the melamine molecule.

2. The presence of the peaks at 7.4 and 8.5 on the X-ray chart of melamine-MOF and increase the intensity of the peaks indicate the improving of the crystallinity by adding the melamine.

3. Moreover two peaks on Fig. $2 \mathrm{~b}$ chart were appeared at 2-theta equals to 26,30 (24). These remarks lead to conclude that there are an interaction between the Cu-MOF and melamine as conclude from the IR chart.

\subsection{Scanning electron microscope (SEM)}

To study the morphologies of the prepared samples, the prepared powder exposed to SEM examination. Fig. 3 ( $a$ and $b$ ) represents the images of the SEM. The images showed that for the Cu-MOF and MCuMOF have rods and long - bar structure. These rods are distributed randomly while more clearance of the 
MCu-MOF is observed. This emphasis the IR and the X-ray measurements. The surface area of Cu-MOF and MCU-MOF were calculated from the BET measurements, for the prepared Cu-MOF, the specific surface area equals to $1350\left(\mathrm{~m}^{2} \mathrm{~g}^{-1}\right)$ and pore volume $0.78\left(\mathrm{~cm}^{3} \mathrm{~g}^{-1}\right)$ while the MCu-MOF has specific surface area $1410\left(\mathrm{~m}^{2} \mathrm{~g}^{-1}\right)$ and pore volume $0.90\left(\mathrm{~cm}^{3} \mathrm{~g}^{-1}\right)$ as shown in Table 1. The results indicate that both the surface area and pore volume improves by introducing the melamine molecules into the Cu-MOF. In all cases, they have high surface are which candidate to use in different applications such a removal of some heavy metals and their antibacterial and anti-fungi effects.

Table 1

BET of CU-MOF and MCU-MOF

\begin{tabular}{|lll|}
\hline materials & BET Surface area $\left(\mathbf{m}^{2} \mathbf{~ g}^{-1}\right)$ & Pore volume $\left(\mathbf{c m}^{\mathbf{3}} \mathbf{~ g}^{-\mathbf{1}}\right)$ \\
\hline Cu-MOF & 1350 & 0.78 \\
\hline MCU-MOF & 1410 & 0.9 \\
\hline \multirow{3}{*}{ 3.4. The thermal analysis }
\end{tabular}

Figure 4(a, b), represents the TG curves of Cu-MOF and MCu-MOF. For Cu-MOF, Fig. 4a, the thermal gravimetric curves it is showed that the curve passes through three definite regions. The first one lies between the room temperature and $300^{\circ} \mathrm{C}$, this stage represents the water loss however it is chemical or physical absorbed water. The second step accompanied by great weight loss between $300{ }^{\circ} \mathrm{C}$ to $420^{\circ} \mathrm{C}$, it represents the main degradation of Cu-MOF built. The third step lies above 420 and it represent the formation of $\mathrm{Cu}-\mathrm{O}$ as residual of the degradation (25). For MCu-MOF, fourth stages were appeared through the main degradation. This phenomenon may be attributed to splitting the organic fragment from the inorganic copper fragments. The results of the TG analysis showed that both the Cu-MOF and Mcu-MOF are thermally stable until $400^{\circ} \mathrm{C}$ and the stability increases by adding melamine to $700{ }^{\circ} \mathrm{C}$ as shown in Fig. 4b.

\subsection{Bioactivity test}

The bioactivity effects of both Cu-MOF and MCu_MOF were tested for five bacterial species, (Bacillus subtilis ATCC6633, Lactobacillus cereus ATCC 14579 and Staphylococcus aureus ATCC29213), Gramnegative bacteria (Escherichia coli ATCC 25922 and Salmonella enterica ATCC 25566), and fungus (Aspergillus niger NRC53). It is found that $\mathrm{Cu}-\mathrm{MOF}$ and MCu-MOF compounds have insignificale activity when compared with terphthalic acid, while for Escherichia coli ATCC 25922, MCu-MOF have a considerable effects, where the inhabitation zone increase from 10 to 17. For Fungus, Aspergillus niger NRC53, both the Cu-MOF and MCu-MOf have a great effects where the inhibition zone increase from zero for terphthalic acid to record $11 \mathrm{~mm}$ as shown in Table 2 and Figs. (5-10). 
Table 2

Antimicrobial activity of prepared samples.

\begin{tabular}{|lllll|}
\hline \multirow{2}{*}{ Microorganism } & & \multicolumn{3}{l|}{ Inhibition zone $(\mathrm{mm})$} \\
\cline { 3 - 5 } & & Cu-MOF & MCu-MOF & Terphthalic acid \\
\hline \multirow{2}{*}{ Gram positive bacteria } & Bacillus subtilis & 11 & 10 & 10 \\
\cline { 2 - 5 } & Lactobacillus cereus & 10 & 10 & 11 \\
\cline { 2 - 5 } Gram negative bacteria & Staphylococcus aureus & 10 & 10 & 9 \\
\cline { 2 - 5 } & Escherichia coli & 11 & 17 & 10 \\
\cline { 2 - 5 } Fungi & Salmonella enterica & 9 & 9 & 9 \\
\hline
\end{tabular}

\section{Conclusion}

From the analysis of the measurements it concludes that:-

1. Both Cu-MOF and MCu-MOF can be formed by applying the hydrothermal route.

2. The prepared powders have antimicrobial effects on the gram positive and gram negative of bacteria and fungi.

\section{Declarations}

\section{Acknowledgement}

The authors submit their acknowledgment to their institute (National Research Centre, Cairo, Egypt) for encouragement the team work to do this work.

\section{References}

1. T. Ding, X. Liao, Q. Dong, X. Xuan, S. Chen, X. Ye, X. D. Liu, (2018). Predictive modeling of microbial single cells: Areview. Critical Reviews in Food Science and Nutrition, 58(5), 711-725. https://doi.org/10.1080/10408398.2016.1217193.

2. B. Hamandi, S. Husain, A. Humar, E. Papadimitropoulos, (2014). Impact of infectious disease consultation on the clinical and economic outcomes of solid organ transplant recipients admitted for infectious complications. Clinical Infectious Diseases, 59(8), 1074-1082. https://doi.org/10.1093/cid/ciu522.

3. S.Kargozar, M. Montazerian, S. Hamzehlou, H. Kim, F. Baino, (2018). Mesoporous bioactive glasses: Promising platforms for antibacterial strategies. Acta Biomaterialia, 81, 1-19. 
https://doi.org/10.1016/j.actbio.2018.09.052.

4. X. Liao, P. Cullen, D. Liu, A. Muhammad, S. Chen, X. Ye, T. Ding, (2018). Combating Staphylococcus aureus and its methicillin resistance gene (mecA) with cold plasma. Science of the Total Environment, 645, 1287-1295. https://doi.org/ 10.1016/j.scitotenv.2018.07.190.

5. X. Liao, Y. Ma, E. Daliri, S. Koseki, S. Wei, D. Liu, T. Ding, (2020). Interplay of antibiotic resistance and food-associated stress tolerance in foodborne pathogens. Trends in Food Science and Technology, 95, 97-106. https://doi:10.1016/j.tifs.2019.11.006.

6. M. Shen, N. Duan, s. Wu, Y. Zou, Z. Wang, (2019). Polydimethylsiloxane gold nanoparticle composite film as structure for aptamerbased detection of Vibrio parahaemolyticus by surface-enhanced Raman spectroscopy. Food Analytical Methods, 12(2), 595-603. https://doi.org/10.1007/s12161018-1389-5.

7. J. Liu, K. Chamakura, R. Perez-Ballestero, S. Bashir, (2012). Historical overview of the first two waves of bactericidal agents and development of the third wave of potent disinfectants. In R. Nagarajan (Ed.), Nanomaterials for biomedicine (Vol. 1119, pp. 129-154). Washington, DC: American Chemical Societ.

8. K. Ong, Y. Cheow, S. Lee, (2017). The role of reactive oxygen species in the antimicrobial activity of pyochelin. Journal of Advanced Research, 8(4), 393-398. https://doi.org/10.1016/j.jare.2017.05.007.

9. F. Vatansever, W. de Melo, P. Avci, D. Vecchio, M. Sadasivam, a. Gupta, m. Hamblin, (2013). Antimicrobial strategies centered around reactive oxygen species-bactericidal antibiotics, photodynamic therapy, and beyond. FEMS Microbiology Reviews, 37(6), 955-989. https://doi.org/10.1111/1574-6976.12026.

10. J. Li, J. Sculley, H. Zhou, (2012). Metal-organic frameworks for separations. Chemical Reviews, 112(2), 869-932. https://doi.org/10.1021/cr200190s.

11. S. Meek, J. Greathouse, M. Allendorf, (2011). Metal organic frameworks: A rapidly growing class of versatile nano-porous materials. Advanced Materials, 23(2), 249-267. https://doi.org/10.1002/adma.201002854.

12. X. Unamuno, E. Imbuluzqueta, F. Salles, P. Horcajada, M. Blanco-Prieto, (2018). Biocompatible porous metal-organic framework nanoparticles based on $\mathrm{Fe}$ or $\mathrm{Zr}$ for gentamicin vectorization. European Journal of Pharmaceutics Biopharmaceutics, 132, 11-18. https://doi.org/10.1016/j.ejpb.2018.08.013.

13. A. Taher, D. Kim, I. Lee, (2017). Highly efficient metal organic framework (MOF)-based copper catalysts for the base-free aerobic oxidation of various alcohols. RSC Adv. 7 (29), 17806-17812. https://doi.org/10.1039/C6RA28743C.

14. A. Czaja, N. Trukhan, U. Muller, (2009). Industrial applications of metal-organic frameworks. Chemical Society Reviews, 38(5), 1284-1293. https://doi.org/10.1039/b804680h.

15. Y. Lee, J. Kim, W. Ahn, (2013). Synthesis of metal-organic frameworks: A mini review. Korean Journal of Chemical Engineering, 30(9), 1667-1680. https://doi.org/10.1007/s11814-013-0140-6. 
16. N. Stock, S. Biswas, (2012). Synthesis of metal-organic frameworks (MOFs): Routes to various MOF topologies, morphologies, and composites. Chemical Reviews, 112(2), 933969.https://doi.org/10.1021/cr200304e.

17. C. Vaitsis, G. Sourkouni, c. Argirusis, (2019).Metal Organic Frameworks (MOFs) and ultrasound: Areview. Ultrasonics Sonochemistry, 52, 106-119. https://doi.org/10.1016/j.ultsonch.2018.11.004.

18. N. Yin, K. Wang, Y. Xia, Z. Li, (2018). Novel melamine modified metal-organic frameworks for remarkably high removal of heavy metal $\mathrm{Pb}$ (II). Desalination 430, 120-127. https://doi.org/10.1016/j.desal.2017.12.057.

19. W. El-Sawy, N. Mohamed, E. Kassem, A. ElAty, (2015). Synthesis of new benzofuran derivatives and evaluation of their antimicrobial activities. Res J Pharm, Biol Chem Sci 6, 213-224. https://www.researchgate.net/publication/311765825.

20. R. Ahmad, G. Mehrorang, (2020). Application of Cu-based metal-organic framework (Cu-BDC) as a sorbent for dispersive solid-phase extraction of gallic acid from orange juice samples using HPLC-UV method. Arabian Journal of Chemistry, 13, 5218-5228.

https://doi.org/10.1016/j.arabjc.2020.02.020.

21. N. Sahiner, S. Demirci, K. Sel, (2016). Covalent organic framework based on melamine and dibromoalkanes for versatile use, J. Porous. Mater. 23, 1025-1035. http://dx.doi.org/10.1007\%2Fs10934-016-0160-9.

22. L. Zang, J. Qiu, C. Yang, (2016). Preparation and application of conducting polymer/Ag/clay composite nanoparticles formed by in situ UV-induced dispersion polymerization, Sci. Rep. 6, 20470. http://dx.doi.org/10.1038/srep20470 (2016).

23. Kaur, R., Kaur, A., Umar, A., Anderson, W.A., Kansal, S.K., 2019. Metal organic framework (MOF) porous octahedral nanocrystals of Cu-BTC: synthesis, properties and enhanced adsorption properties. Mater. Res. Bull. 109, 124-133. https://dx.doi.org/10.1016/j.materresbull.2018.07.025.

24. X. Han, L. Tian, H. Jiang, (2017). Facile transformation of low cost melamine-oxalic acid into porous graphitic carbon nitride nanosheets with high visible-light photocatalytic performance, RSC Adv. 7 , 14372-14381. https://dx.doi.org/10.1039/c7ra01205e.

25. L. Valenzano, B. Civalleri, S. Chavan, (2011). Disclosing the complex structure of UiO-66 metal organic framework: a synergic combination of experiment and theory,Chem. Mater. 23, 1700-1718. https://doi.org/10.1021/cm1022882.

\section{Figures}




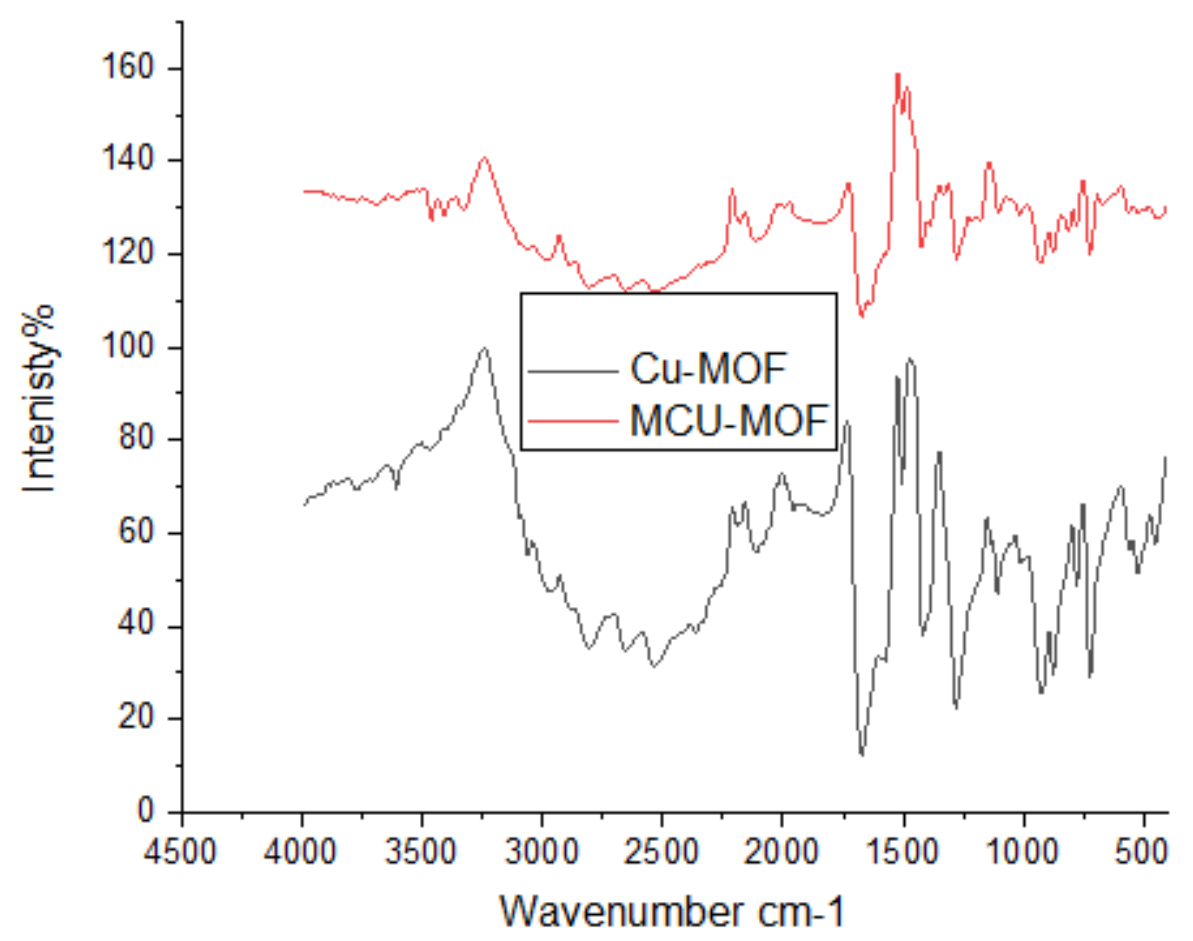

Figure 1

FTIR of Cu-MOF and MCu-MOF

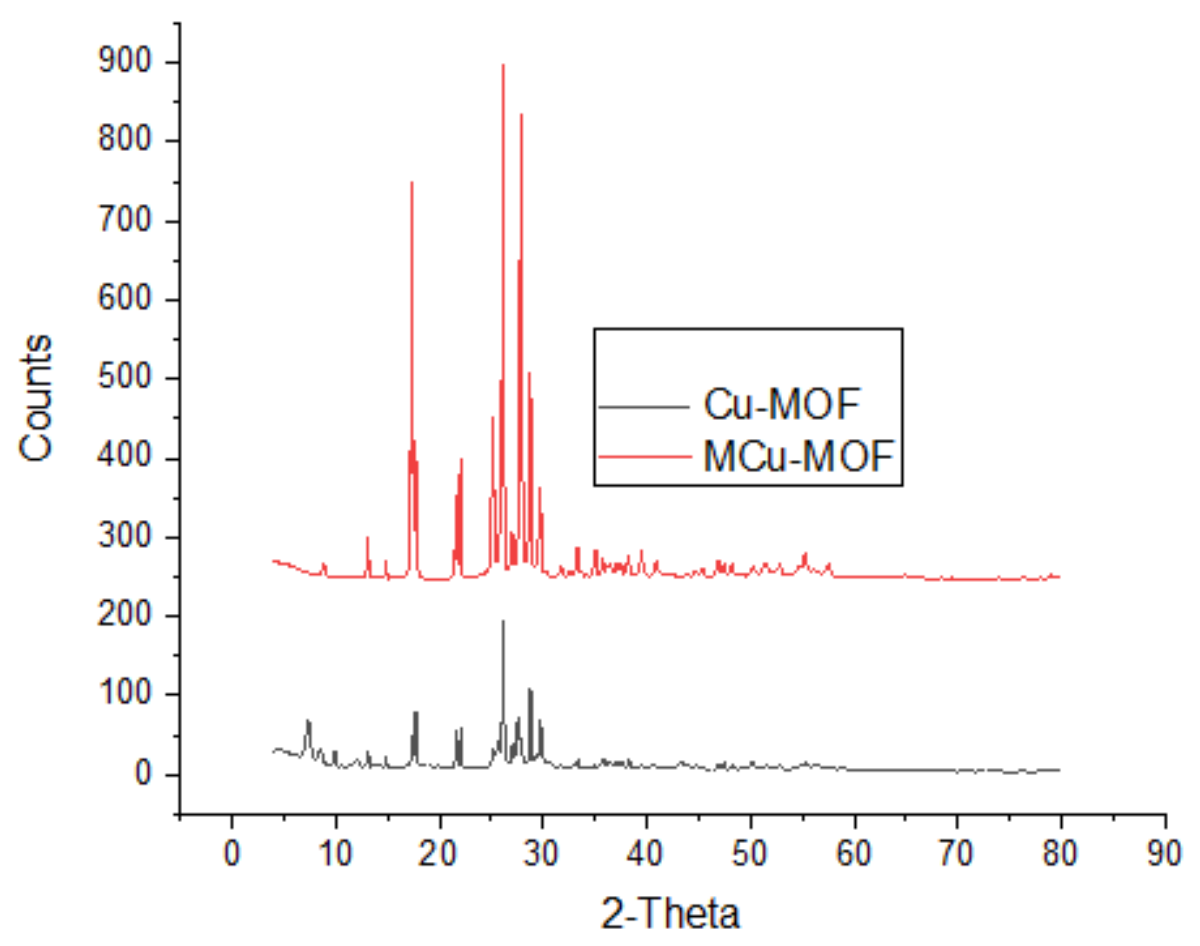

Figure 2

XRD of Cu-MOF and MCu-MOF 


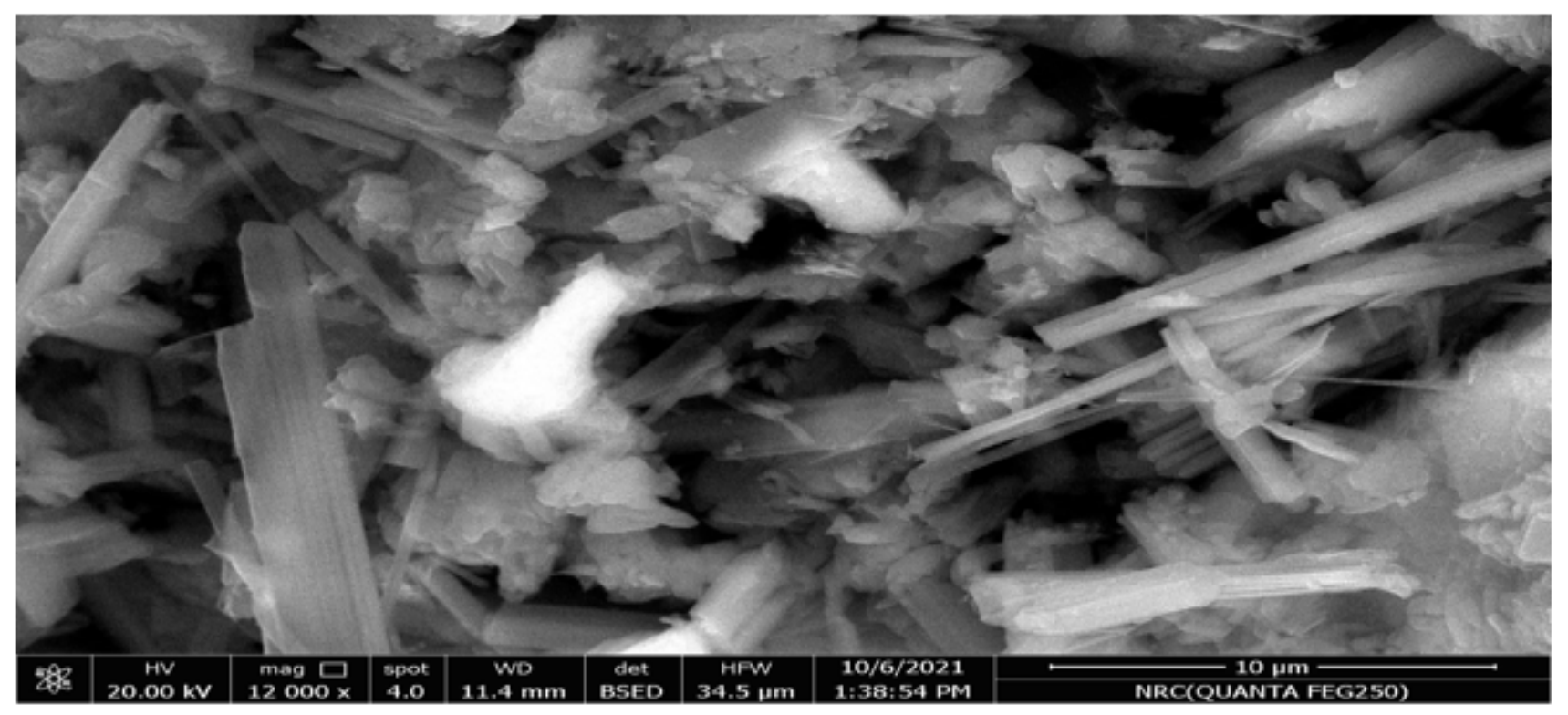

a

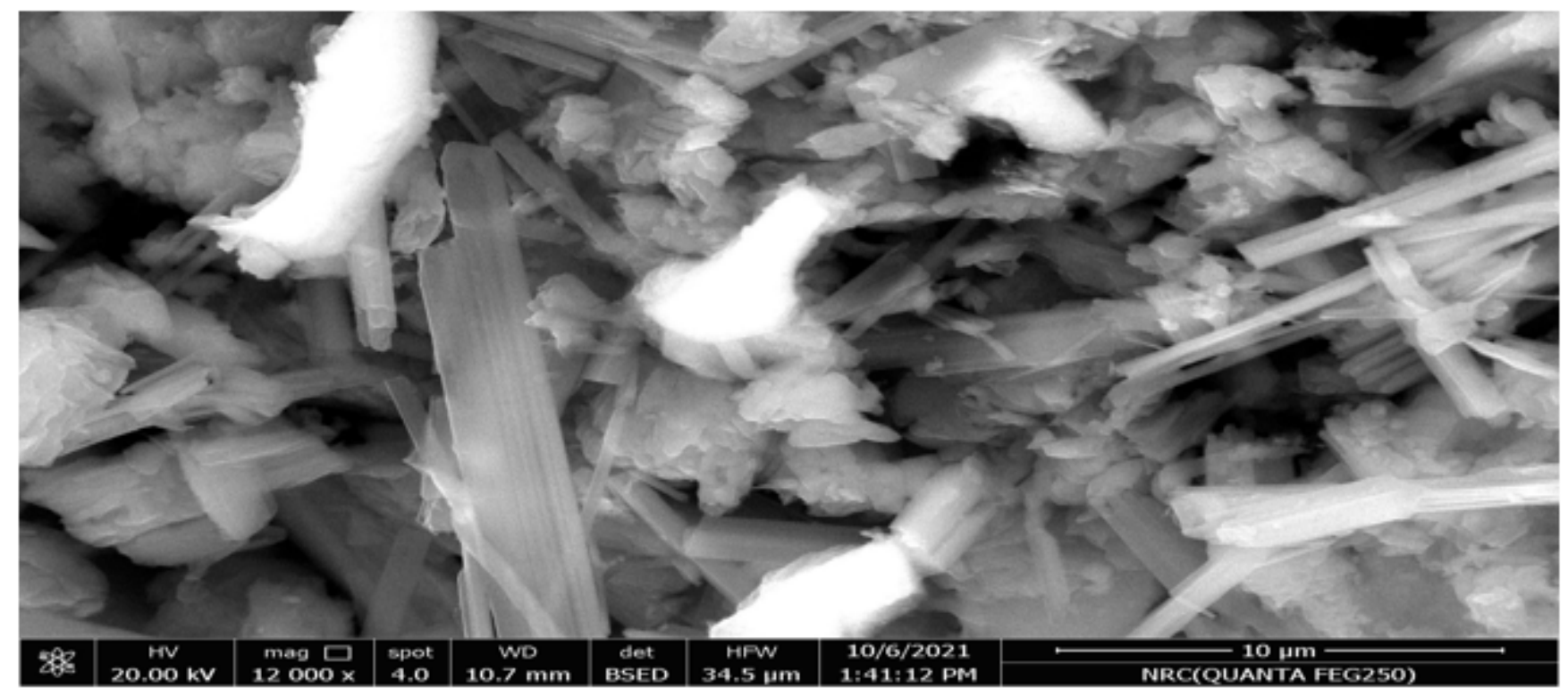

b

Figure 3

SEM of a) Cu-MOF and b) MCu-MOF 


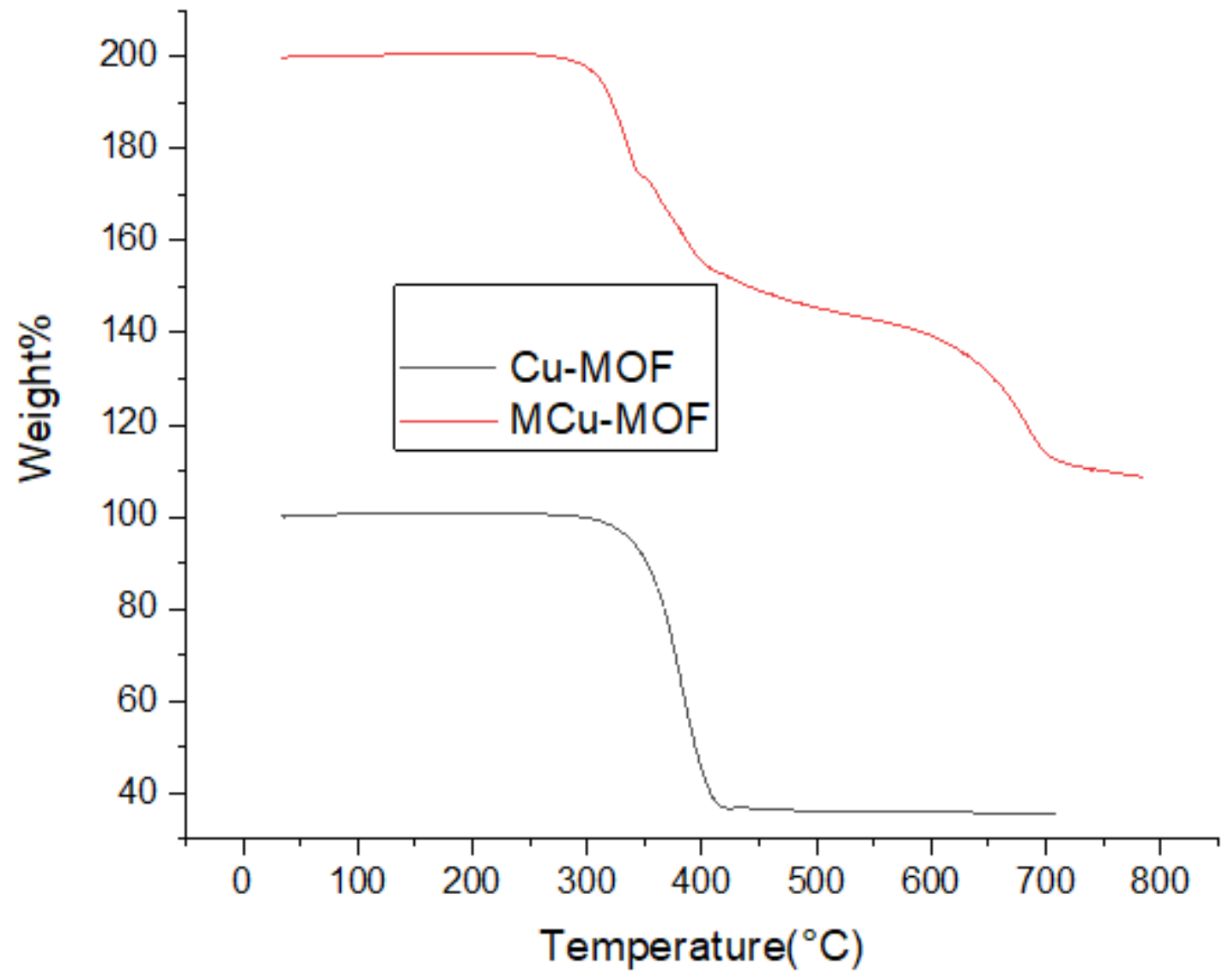

Figure 4

TGA of Cu-MOF and MCu-MOF

Figure 5

Antibacterial activity of Cu-MOF, MCu-MOf and Terphthalic acid on Bacillus subtilis
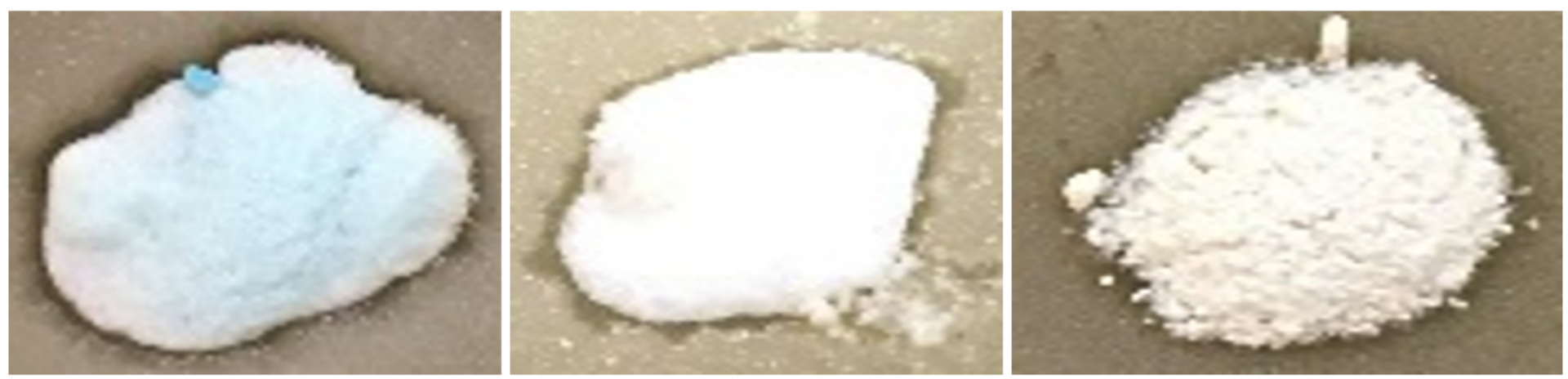

Figure 6

Antibacterial activity of Cu-MOF, MCu-MOf and Terphthalic acid on Lactobacillus cereus 

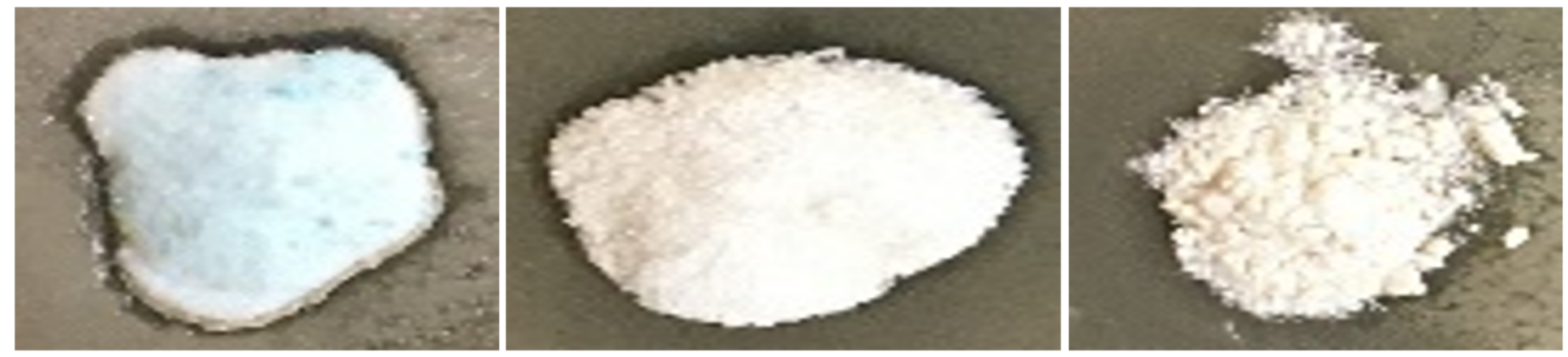

Figure 7

Antibacterial activity of Cu-MOF, MCu-MOf and Terphthalic acid on Staphylococcus aureus
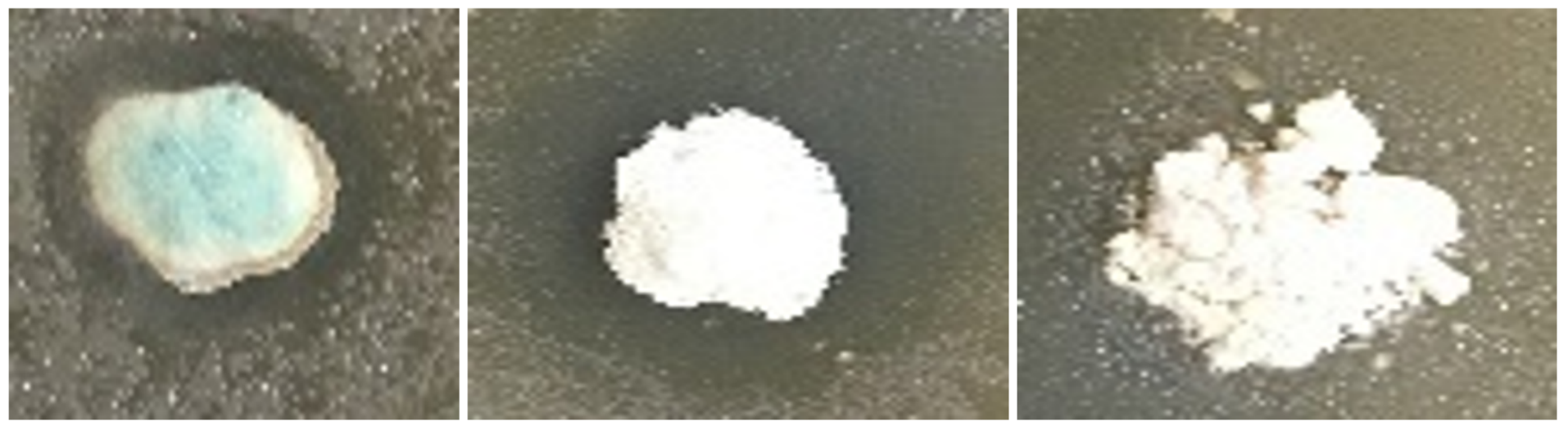

\section{Figure 8}

Antibacterial activity of Cu-MOF, MCu-MOf and Terphthalic acid on Escherichia coli
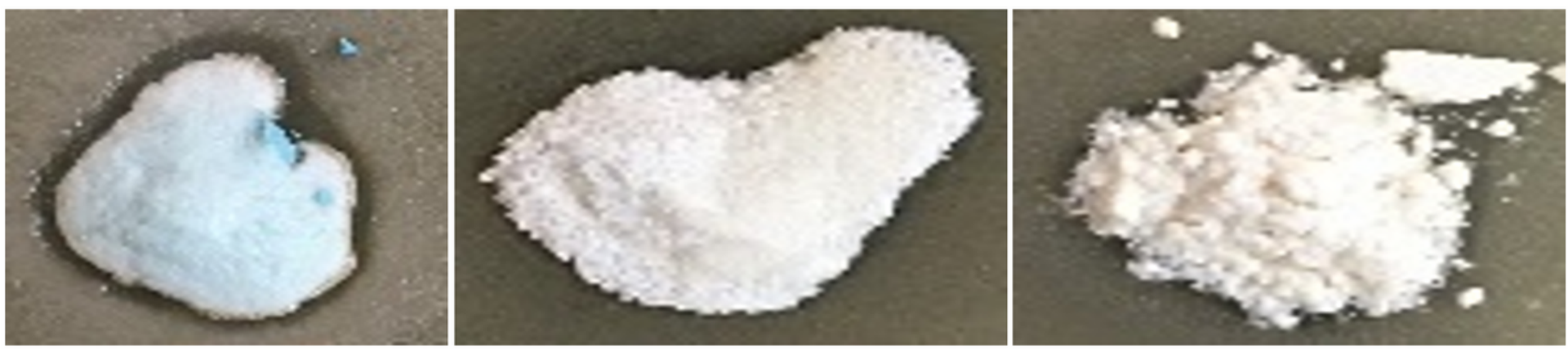

Figure 9

Antibacterial activity of Cu-MOF, MCu-MOf and Terphthalic acid on Salmonella enterica 

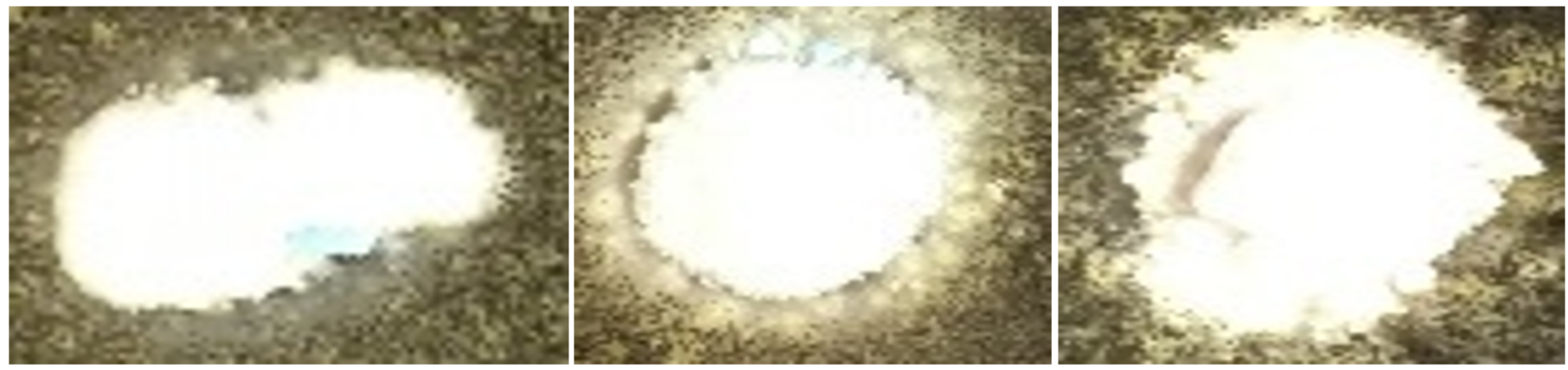

Figure 10

Antifungal activity of Cu-MOF, MCu-MOf and Terphthalic acid on Aspergillus nige 